\title{
Response of swine spleen to Streptococcus suis infection revealed by transcription analysis
}

\author{
Ran $\mathrm{Li}^{1,2+}$, Anding Zhang ${ }^{1,2 \dagger}$, Bo Chen ${ }^{2 \dagger}$, Liu Teng ${ }^{2}$, Ya Wang ${ }^{2}$, Huanchun Chen ${ }^{1,2}$, Meilin Jin ${ }^{1,2^{*}}$
}

\begin{abstract}
Astract
Background: Streptococcus suis serotype 2 (SS2), a major swine pathogen and an emerging zoonotic agent, has greatly challenged global public health. Systematical information about host immune response to the infection is important for understanding the molecular mechanism of diseases.

Results: 104 and 129 unique genes were significantly up-regulated and down-regulated in the spleens of pigs infected with SS2 (WT). The up-regulated genes were principally related to immune response, such as genes involved in inflammatory response; acute-phase/immune response; cell adhesion and response to stress. The down-regulated genes were mainly involved in transcription, transport, material and energy metabolism which were representative of the reduced vital activity of SS2-influenced cells. Only a few genes showed significantly differential expression when comparing avirulent isogenic strain (AHP0197) with mock-infected samples.
\end{abstract}

Conclusions: Our findings indicated that highly pathogenic SS2 could persistently induce cytokines mainly by Tolllike receptor 2 (TLR2) pathway, and the phagocytosis-resistant bacteria could induce high level of cytokines and secrete toxins to destroy deep tissues, and cause meningitis, septicaemia, pneumonia, endocarditis, and arthritis.

\section{Background}

Streptococcus suis (S. suis) is an important pathogen associated with many diseases in pigs, including meningitis, septicaemia, pneumonia, endocarditis, and arthritis. S. suis serotype 2 (SS2) is considered the most pathogenic as well as the most prevalent capsular type among thirty-three serotypes (types 1 to 31,33 , and $1 / 2$ ) in diseased pigs, and it is also the causative agent of serious infections in humans, especially in people in close contact with pig or pork byproducts [1-3]. Two recent large-scale outbreaks of human SS2 epidemics in China (one had 25 cases with 14 deaths in Jiangsu in 1998, the second had 204 cases with 38 deaths in Sichuan in 2005), featured clinical streptococcal toxic shock syndrome, have greatly challenged the global public health [4-7]. Recently, S. suis infection has also caused sporadic human illness in other countries, including Thailand $[8,9]$, United Kingdom [10], Portugal [11], Australia [12], Netherlands [13] and United States [14,15], and

\footnotetext{
*Correspondence: jml8328@126.com

† Contributed equally

'Unit of Animal Infectious Diseases, National Key Laboratory of Agricultural

Microbiology, Huazhong Agricultural University, Wuhan, Hubei, China

Full list of author information is available at the end of the article
}

been recognized as the third most common cause of community acquired bacterial meningitis in Hong Kong and as the leading cause of adult meningitis in Vietnam $[5,16]$.

The past pathogenesis studies were performed mainly on the pathogenic bacteria and as a result, a few virulenceassociated factors have been successfully identified. Polysaccharide capsule has been considered essential for the virulence of the bacterium $[17,18]$, and other factors, such as suilysin, the so-called extracellular protein factor and muramidase-released protein have been shown to be linked to, but not essential for the full virulence of $S$. suis [19]. GapdH [20], Enolase [21,22], FbpS [19], Adhesin [23-27] have been proved to be involved in the adherence and virulence of S. suis. Recently, serum opacity-like factor [28], IgA1 protease [29], D-Alanylation of Lipoteichoic Acid [30] and pgdA [31] were identified as important factors in S. suis virulence. In addition, SalK/SalR [32] and CovR [33] were found to affect the virulence of S. suis Chinese isolates. These studies have contributed to the understanding of S. suis pathogenesis and also suggested that host responses also play essential roles in the development of the diseases.
Ciomed Central

C 2010 Li et al; licensee BioMed Central Ltd. This is an Open Access article distributed under the terms of the Creative Commons Attribution License (http://creativecommons.org/licenses/by/2.0), which permits unrestricted use, distribution, and reproduction in any medium, provided the original work is properly cited. 
Inducing excessive inflammation is recognized as one of the reasons why highly invasive SS2 strain could cause severe diseases [31,34]. A few previous studies indicated that high level of cytokines and chemokines could be released by human brain microvascular endothelial cells [35], a whole-blood culture system [36], macrophages [37] and monocytes [38] stimulated by SS2, and have important roles in the initiation and development of inflammation and meningitis [39]. More direct proofs were the studies on mice with different genetic background, which indicated that IL-10 was responsible, at least in part, for the high survival, which suggested that aberrant innate immune response contributed to SS2 diseases [40].

To be aware of the information about host immune response would enable people to better understand the disease. Transcriptional response of alveolar macrophages to SS2 has been performed and the results indicated that NF-kB and MAP-kinases signaling pathways were induced upon interaction with SS2 [41]. However, it is not easy to get more information since the primary macrophages are so sensitive to the interference. Spleen plays an important role in immune response and could be an ideal target to study host immune response against infection $[42,43]$. In the present study, the gene expression profiles of swine spleens which suffered from highly pathogenic SS2, avirulent isogenic strain and PBS respectively were investigated to reveal the host immune response to SS2 and the contributions of host response to SS2 diseases.

\section{Results}

\section{Transcriptome analysis}

The transcriptome analysis indicated that 14,992, 15,487 and 15,757 probe sets, corresponding to $62.1 \%, 64.2 \%$ and $65.3 \%$ of all probe sets, were detected in WT, $\triangle$ HP0197 and mock-infected pig spleens respectively (Additional file 1). The expression profiles of porcine spleens challenged with WT 3 days post inoculation were compared with those of the mock-infected group. After quantile normalization and statistical analysis, 1014 transcripts were identified at the global false discovery rate (FDR) of $10 \%$ (Additional file 2). Furthermore, the criteria of a two-fold or greater change in differential expression and a FDR of $10 \%$ were chosen to determine up-regulated and down-regulated genes in the WT infected replicates. Using these criteria, 120 and 132 transcripts, representing 104 and 129 unique genes, were significantly up-regulated and downregulated respectively (Additional file 3 ). However, only a few genes showed significantly differential expressions when comparing $\triangle \mathrm{HP} 0197$ with mock-infected samples (Figure 1A).
Of the 233 unique DE transcripts, 158 transcripts could be determined based on BLASTX searches and annotated with DAVID or by searching against the GenBank database (Figure 1B). Among these, 135 unique genes were grouped into 39 categories based on biological process Gene Ontology (GO) terms or according to their potential Biology Process Classification by referring to recent publications (Figure $1 C$ ). Unsurprisingly, the majority of genes were related to the immune response, Transcription, Transport, material and energy metabolism, etc. (Table 1).

\section{Validation of microarray data by quantitative real-time PCR (qPCR)}

The qPCR was performed to validate the expression patterns during infection for specific genes identified in the microarray assay. In order to validate the differential expression of various identified genes, 16 up-regulated genes, with the increase ranging from 2.0-fold to 18.6fold, and 3 down-regulated genes, with the decrease ranging from 2.5-fold to 5.9-fold, were selected for qPCR analysis. All the selected down-regulated genes could be amplified from the control samples but failed to achieve significant detectable signs from WT-infected spleens, except for $A L O X 15$ which showed 3.2-fold down-regulated expression. All selected up-regulated genes showed higher expression in WT-infected samples than in the control samples (Table 2). Though variation in fold changes could be observed between qPCR and microarray (Table 2), the differential expression patterns were coincident between the results of the two techniques, which indicated the reliability of the microarray analysis.

\section{Induction of inflammasomes and acute phase proteins by SS2 infection}

Highly pathogenic SS2 infection could cause up-regulated expression of a large set of genes involved in the inflammatory response and acute phase proteins by microarray analysis. IL-1B, IL- 6 and IL- 8 could be induced by foreign pathogens and play essential roles in controlling infections $[5,44]$. However, they may also cause pathology when these productions are excessive or uncontrolled [45]. Ye et al. also found that significantly high level of cytokines could be induced by highly pathogenic SS2 strain and play important roles in sepsis [34], which is in coincidence with ours. In addition, quite a few genes related to inflammatory response were found up-regulated, such as S100 family proteins (S100A8, S100A9 and S100A12) [46], Pentraxin 3 [47] and Resistin $[48,49]$. They play important roles in mediating inflammatory responses, recruiting inflammatory cells to sites of tissue damage or contributing to resisting the invasion of various pathogens. 


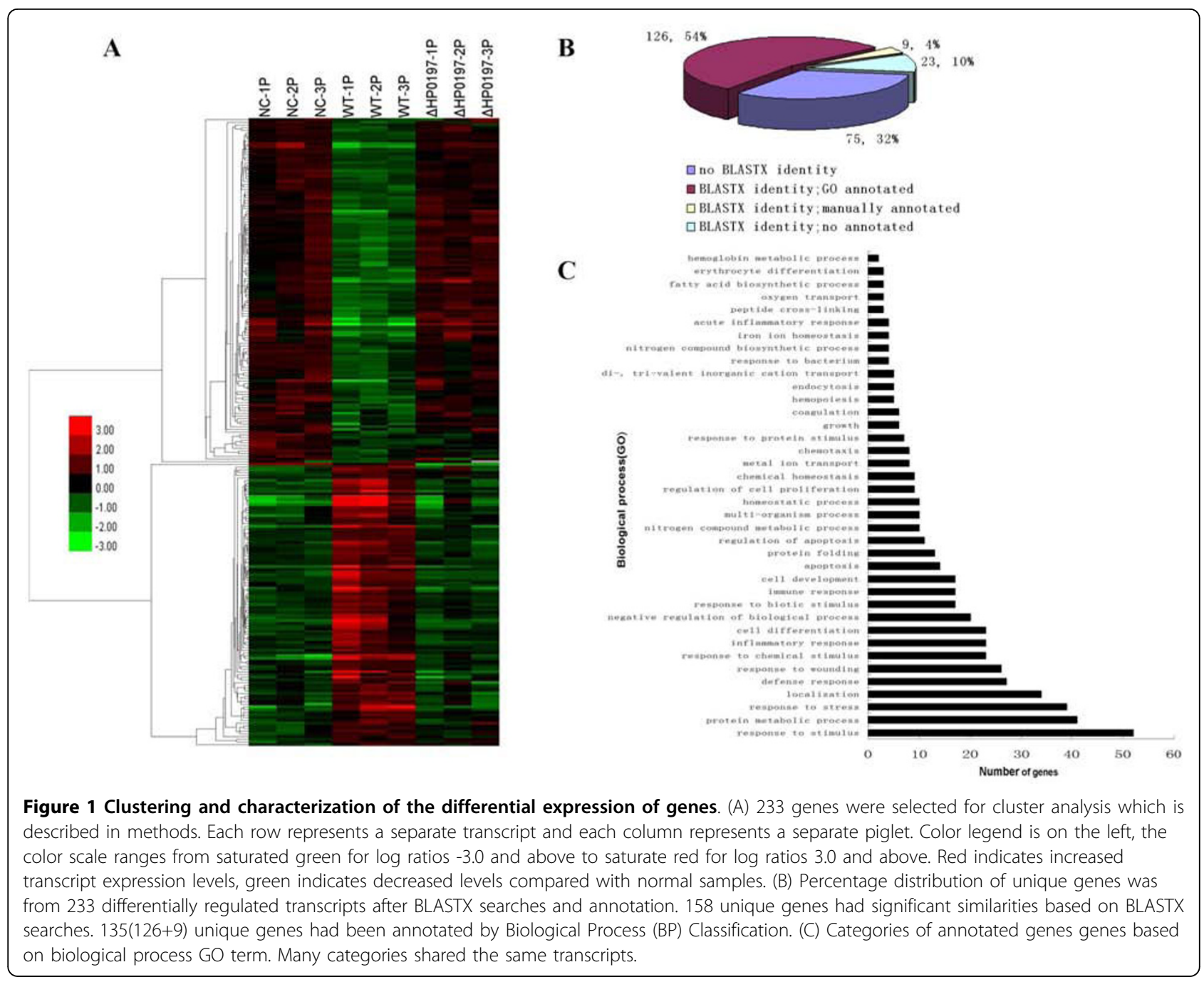

Acute phase proteins (APPs), such as Lactotransferrin [50], Haptoglobin [51], Serum amyloid A 2 [52] and coagulation factor XIII, were involved in physiologic reactions initiated early in the inflammatory process [53], and could be a response to S. suis infection [54]. CEBPD belonging to the CCAAT-enhancer binding protein (CEBP) family which is crucial in the regulation of genes involved in immunity and inflammation. These up-regulated genes are the representative of host acute response struggling to eliminate invading pathogens.

\section{Induction of genes related in cell adhesion and stress response}

Cell adhesion molecules (CAMs) have been implicated in the regulation of a wide variety of fundamental cellular processes, such as cell adhesion, cell polarization, survival, movement, and proliferation [55]. E-selectin is a cell adhesion molecule expressed on endothelial cells activated by cytokines, and plays an important role in recruiting leukocytes to the site of injury [56]. Versican can bind adhesion molecules on the surface of inflammatory leukocytes [57] and act as a TLR2 agonist in inducing the release of proinflammatory cytokines [58]. Thrombospondin 1 is an adhesive glycoprotein that mediates cell-to-cell and cell-to-matrix interactions and it could interact with numerous proteases involved in angiogenesis [59]. Mucosal vascular addressin cell adhesion molecule 1 is predominantly expressed on high endothelial venules in inflamed tissues, and could assist the extravasations of leucocyte [60]. The up-regulation of cell adhesion molecules after SS2 infection would contribute to recruiting leukocytes to the site of infection, which could control infection.

Genes related to oxidative stress and homeostasis were also identified to be up-regulated. SOD2 provides vital protection against reactive oxygen species (ROS), thus protecting tissues from damage in a broad range of disease states. The secretion of PGE2, together with nitric 
Table 1 Different expression of genes in spleens after S. suis infection 3 days

\begin{tabular}{|c|c|c|c|c|}
\hline Function classification & $\begin{array}{l}\text { ENTREZ } \\
\text { GENE_ID }\end{array}$ & Description & $\begin{array}{c}\text { Fold } \\
\text { change }\end{array}$ & $\begin{array}{c}\text { Q-value } \\
(\%)\end{array}$ \\
\hline \multicolumn{5}{|l|}{ Inflammatory response } \\
\hline & 929 & CD14 Antigen & 3.4 & 1.222 \\
\hline & 6279 & S100 Calcium binding protein A8 & 19.3 & 1.508 \\
\hline & 6280 & S100 Calcium binding protein A9 & 16.1 & 0 \\
\hline & 3588 & Interleukin 10 receptor, beta & 2.7 & 3.911 \\
\hline & 5743 & Prostaglandin-Endoperoxide synthase 2 & 4.7 & 7.146 \\
\hline & 7057 & Thrombospondin 1 & 2.4 & 6.387 \\
\hline & 3576 & Interleukin 8 & 5.6 & 6.387 \\
\hline & 9547 & Chemokine (C-X-C Motif) Ligand 14 & 2.0 & 8.898 \\
\hline & 6283 & S100 Calcium binding protein A12 & 18.6 & 0 \\
\hline & 2908 & Nuclear receptor subfamily 3 , group C, member 1 & 0.5 & 6.882 \\
\hline & 6363 & Chemokine (C-C Motif) Ligand 19 & 2.2 & 1.508 \\
\hline & 7097 & Toll-like receptor 2 & 2.0 & 6.387 \\
\hline & 2920 & Chemokine (C-X-C Motif) Ligand 2 & 7.3 & 3.385 \\
\hline & 246 & Arachidonate 15-Lipoxygenase & 0.2 & 2.181 \\
\hline & 7052 & Transglutaminase 2 & 2.1 & 6.387 \\
\hline & 9332 & CD163 antigen & 11.7 & 0 \\
\hline & 6288 & Serum amyloid A1 & 6.4 & 1.222 \\
\hline & 3553 & Interleukin 1, beta & 16.7 & 6.387 \\
\hline & 3569 & Interleukin 6 (Interferon, Beta 2) & 4.8 & 6.387 \\
\hline & 56729 & Resistin & 3.7 & 7.146 \\
\hline \multicolumn{5}{|l|}{ Response to stress } \\
\hline & 1153 & Cold inducible rna binding protein & 0.43 & 5.612 \\
\hline & 3320 & Heat shock protein 90Kda alpha class A member 1 & 3.2 & 8.898 \\
\hline & 6916 & Thromboxane A synthase 1 & 2.6 & 3.911 \\
\hline & 10963 & Stress-induced-phosphoprotein 1 & 2.5 & 0 \\
\hline & 130872 & AHA1, activator of heat shock 90Kda protein ATPase homolog 2 & 2.6 & 1.508 \\
\hline & 3337 & Dnaj (Hsp40) homolog, subfamily B, member 1 & 2.8 & 1.222 \\
\hline & 871 & $\begin{array}{l}\text { Serpin peptidase inhibitor, clade H (Heat Shock Protein 47), } \\
\text { member } 1\end{array}$ & 2.7 & 1.222 \\
\hline & 10808 & Heat shock 105Kda/110Kda protein 1 & 3.3 & 0 \\
\hline & 3301 & Dnaj (Hsp40) homolog, subfamily A, member 1 & 2.4 & 0 \\
\hline & 3304 & Heat Shock 70Kda Protein 1A & 11.1 & 0 \\
\hline \multicolumn{5}{|l|}{ Coagulation } \\
\hline & 5328 & Plasminogen activator, urokinase & 2.0 & 6.387 \\
\hline & 2162 & Coagulationfactor XIII, A1 polypeptide & 6.8 & 3.385 \\
\hline \multicolumn{5}{|l|}{ Signal transduction } \\
\hline & 9465 & A kinase anchor protein 7 & 0.5 & 6.698 \\
\hline & 8519 & Interferon induced transmembrane protein 1 & 2.0 & 6.387 \\
\hline & 115265 & Dna-damage-inducible transcript 4-like & 0.3 & 2.181 \\
\hline & 9770 & Ras association (Ralgds/Af-6) domain family 2 & 2.4 & 6.387 \\
\hline & 9510 & Adamm etallopeptidase with thrombospondin type 1 motif, 1 & 2.3 & 0 \\
\hline & 1363 & Carboxypeptidase E & 0.44 & 6.698 \\
\hline & 54210 & Triggering receptor expressed on myeloid cells 1 & 3.2 & 6.387 \\
\hline & 9289 & G protein-coupled receptor 56 & 0.46 & 6.698 \\
\hline & 7043 & Transforming growth factor, beta 3 & 2.1 & 4.116 \\
\hline \multicolumn{5}{|l|}{ Transcription } \\
\hline & 2353 & V-Fos fbj murine osteosarcoma viral oncogene homolog & 2.8 & 3.911 \\
\hline & 84969 & Chromosome 20 open reading frame 100 & 0.3 & 2.541 \\
\hline & 55885 & Lim domain only 3 & 0.3 & 2.181 \\
\hline & 3726 & Jun B proto-oncogene & 2.6 & 7.146 \\
\hline & 91 & Activin a receptor, type ib & 3.4 & 1.222 \\
\hline
\end{tabular}


Table 1 Different expression of genes in spleens after S. suis infection $\mathbf{3}$ days (Continued)

\begin{tabular}{|c|c|c|c|c|}
\hline & 116448 & Oligodendrocyte transcription factor 1 & 2.4 & 6.387 \\
\hline & 79365 & Basic helix-loop-helix domain containing, class B, 3 & 0.4 & 2.181 \\
\hline & 64919 & B-cell cll/lymphoma 11B & 0.5 & 2.181 \\
\hline & 23635 & Single-stranded dna binding protein 2 & 0.4 & 2.541 \\
\hline & 23414 & Zinc finger protein, multitype 2 & 0.5 & 6.698 \\
\hline & 7552 & Zinc finger protein $6(\mathrm{Cmpx} 1)$ & 0.5 & 3.385 \\
\hline & 6920 & Transcription elongation factor A (SII), 3 & 2.2 & 6.387 \\
\hline & 4783 & Nuclear factor, interleukin 3 regulated & 2.4 & 3.911 \\
\hline & 1052 & CCAAT/Enhancer binding protein (C/EBP), delta & 3.1 & 0 \\
\hline \multicolumn{5}{|l|}{ Cell adhesion } \\
\hline & 6401 & Selectin E & 3.5 & 1.222 \\
\hline & 8174 & Mucosal vascular addressin cell adhesion molecule 1 & 2.3 & 6.387 \\
\hline & 5067 & Contactin 3 & 0.5 & 6.794 \\
\hline & 4867 & Nephronophthisis 1 (Juvenile) & 0.4 & 3.911 \\
\hline & 1462 & Chondroitin sulfate proteoglycan 2 (Versican) & 9.1 & 0 \\
\hline & 960 & CD44 antigen & 2.3 & 2.541 \\
\hline \multicolumn{5}{|l|}{ Ubiquitin cycle } \\
\hline & 115123 & Membrane-associated ring finger (C3HC4) 3 & 4.4 & 1.222 \\
\hline & 7317 & Ubiquitin-activating enzyme E1 & 0.4 & 2.181 \\
\hline & 11274 & Ubiquitin specific peptidase 18 & 0.4 & 6.698 \\
\hline & 9666 & Zinc finger daz interacting protein 3 & 0.5 & 6.882 \\
\hline \multicolumn{5}{|l|}{ Transport } \\
\hline & 6556 & Solute carrier family 11 , member 1 & 4.0 & 2.051 \\
\hline & 4057 & Lactotransferrin & 5.9 & 3.385 \\
\hline & 1356 & Ceruloplasmin (Ferroxidase) & 2.3 & 2.541 \\
\hline & 1410 & Crystallin, alpha B & 2.8 & 6.387 \\
\hline & 283652 & Solute carrier family 24, member 5 & 0.4 & 2.181 \\
\hline & 54843 & Synaptotagmin-like 2 & 0.4 & 6.698 \\
\hline & 6947 & Haptocorrin & 8.9 & 0 \\
\hline & 3949 & Low density lipoprotein receptor & 2.1 & 5.612 \\
\hline & 3043 & Hemoglobin, beta & 0.4 & 6.698 \\
\hline & 3042 & Hemoglobin, alpha pseudogene 2 & 0.2 & 2.181 \\
\hline & 3040 & Hemoglobin, alpha 1 & 0.2 & 2.181 \\
\hline & 2554 & Gamma-aminobutyric acid (Gaba) a receptor, alpha 1 & 0.3 & 3.911 \\
\hline & 2288 & Fk506 binding protein 4, 59Kda & 2.2 & 1.222 \\
\hline & 6557 & Solute carrier family 12 , member 1 & 0.4 & 6.882 \\
\hline & 152789 & Janus kinase and microtubule interacting protein 1 & 0.5 & 6.794 \\
\hline \multicolumn{5}{|l|}{ Nucleic acid metabolic process } \\
\hline & 401251 & Muts homolog 5 & 0.5 & 6.698 \\
\hline & 56952 & Phosphoribosyl transferase domain & 0.4 & 2.181 \\
\hline & 51251 & 5'-Nucleotidase, cytosolic lii & 0.4 & 6.698 \\
\hline & 10492 & Synaptotagmin binding, cytoplasmic ma interacting protein & 0.4 & 4.116 \\
\hline & 8347 & Histone 1,H2bd & 2.6 & 6.387 \\
\hline & 8334 & Histone 1, H2ac & 5.6 & 1.222 \\
\hline & 6430 & Splicing factor, arginine/serine-rich 5 & 0.5 & 0 \\
\hline & 4302 & Myeloid/Lymphoid or mixed-lineage leukemia translocated to, 6 & 0.4 & 6.882 \\
\hline \multicolumn{5}{|l|}{ Response to stimulus } \\
\hline & 5806 & $\begin{array}{l}\text { Pentraxin-related gene, rapidly } \\
\text { induced by il- } 1 \text { beta }\end{array}$ & 14.1 & 1.222 \\
\hline & 6372 & Chemokine (C-X-C motif) ligand 6 & 5.5 & 1.222 \\
\hline & 64135 & Interferon induced with helicase c domain 1 & 0.4 & 6.698 \\
\hline & 3240 & Haptoglobin & 4.6 & 0 \\
\hline & 6648 & Superoxide dismutase 2 , mitochondrial & 4.6 & 1.508 \\
\hline
\end{tabular}


Table 1 Different expression of genes in spleens after S. suis infection 3 days (Continued)

\begin{tabular}{|c|c|c|c|c|}
\hline & 1843 & Dual specificity phosphatase 1 & 2.1 & 6.387 \\
\hline \multicolumn{5}{|l|}{ Cell differentiation/development } \\
\hline & 58189 & Wap four-disulfide core domain 1 & 2.1 & 1.222 \\
\hline & 9531 & Bcl2-associated athanogene 3 & 3.7 & 0 \\
\hline & 51454 & Gulp, engulfment adaptor ptb domain containing 1 & 0.4 & 2.181 \\
\hline & 212 & Aminolevulinate, delta-, synthase 2 & 0.4 & 6.698 \\
\hline & 2012 & Epithelial membrane protein 1 & 2.0 & 7.146 \\
\hline & 79689 & Steap family member 4 & 2.8 & 3.911 \\
\hline & 9021 & Suppressor of cytokine signaling 3 & 2.4 & 3.385 \\
\hline & 5270 & Serpin peptidase inhibitor, clade $\mathrm{E}$, member 2 & 2.3 & 3.385 \\
\hline & 1946 & Ephrin-A5 & 0.4 & 3.911 \\
\hline & 85444 & Leucine rich repeat and coiled-coil domain containing 1 & 0.5 & 5.612 \\
\hline & 54873 & Palmdelphin & 0.4 & 5.612 \\
\hline & 10439 & Olfactomedin 1 & 3.3 & 6.387 \\
\hline \multicolumn{5}{|l|}{ Carbohydrate metabolic process } \\
\hline & 4199 & Malic enzyme 1, NADP(+)-dependent, cytosolic & 0.4 & 3.911 \\
\hline & 80760 & Inter-alpha (Globulin) inhibitor H5 & 0.3 & 6.698 \\
\hline & 152831 & Klotho beta & 2.5 & 0 \\
\hline & 3101 & Hexokinase 3 (White Cell) & 2.9 & 6.387 \\
\hline & 3099 & Hexokinase 2 & 2.3 & 8.898 \\
\hline & 1116 & Chitinase 3-like 1 & 2.9 & 8.898 \\
\hline \multicolumn{5}{|l|}{ Protein metabolic process } \\
\hline & 85464 & Slingshot homolog 2 & 2.3 & 1.508 \\
\hline & 51327 & Erythroid associated factor & 0.06 & 0 \\
\hline & 7076 & Timp metallopeptidase inhibitor 1 & 4.4 & 1.222 \\
\hline & 7053 & Transglutaminase 3 & 6.1 & 1.222 \\
\hline & 114907 & F-box protein 32 & 0.4 & 6.794 \\
\hline & 64844 & Membrane-associated ring finger $(\mathrm{C} 3 \mathrm{HC} 4) 7$ & 0.5 & 2.181 \\
\hline & 64172 & O-sialoglycoprotein endopeptidase-like 1 & 0.4 & 2.181 \\
\hline & 55466 & Dnaj (Hsp40) homolog, subfamily A, member 4 & 2.7 & 2.541 \\
\hline & 51056 & Leucine aminopeptidase 3 & 2.0 & 8.898 \\
\hline & 2289 & Fk506 binding protein 5 & 2.5 & 6.387 \\
\hline & 26235 & F-box and leucine-rich repeat protein 4 & 0.5 & 6.698 \\
\hline \multicolumn{5}{|l|}{$\begin{array}{l}\text { Nitrogen compound metabolic } \\
\text { process }\end{array}$} \\
\hline & 383 & Arginase & 0.2 & 2.181 \\
\hline & 64850 & Alanine-glyoxylate aminotransferase 2-like 1 & 0.2 & 6.882 \\
\hline & 6799 & $\begin{array}{l}\text { Sulfotransferase family, cytosolic, 1A, phenol-preferring, member } \\
2\end{array}$ & 2.0 & 6.387 \\
\hline & 8974 & $\begin{array}{l}\text { Procollagen-proline, 2-oxoglutarate 4-dioxygenase, alpha } \\
\text { polypeptide ii }\end{array}$ & 3.2 & 6.387 \\
\hline \multicolumn{5}{|l|}{ Others } \\
\hline & 129446 & Cardiomyopathy associated 3 & 0.3 & 2.181 \\
\hline & 128218 & Transmembrane protein 125 & 2.0 & 8.898 \\
\hline & 57763 & Ankyrin repeat, family A, 2 & 0.4 & 2.181 \\
\hline & 29970 & Schwannomin interacting protein 1 & 0.5 & 6.794 \\
\hline & 23336 & Desmuslin & 0.5 & 6.882 \\
\hline & 590 & Butyrylcholinesterase & 0.5 & 4.116 \\
\hline & 84649 & Diacylglycerol o-acyltransferase homolog 2 & 3.2 & 1.222 \\
\hline & 79887 & Hypothetical protein Flj22662 & 3.5 & 6.387 \\
\hline
\end{tabular}

DE genes which putative functions assigned based on GO term and manual annotation. Manual annotations were listed in italics. Many genes with multiple functions were only listed in one category according to specific biology processes. " $\mathrm{FC} \geq 2$ " represents up regulation (infection/control), " $\mathrm{FC} \leq 0.5$ " represents down regulation. 
Table 2 Validation of microarray results by qPCR

\begin{tabular}{llcc}
\hline Gene & Accession & $\begin{array}{c}\text { Microarray fold } \\
\text { change }\end{array}$ & $\begin{array}{c}\text { qPCR fold change } \\
\text { (p-value) }\end{array}$ \\
\hline IL1B & CK468468 & 16.7 & $258.3(0.0117)$ \\
S100A9 & BI402402 & 16.1 & $137.2(0.0007)$ \\
S100A12 & CB475695 & 18.6 & $76.7(<0.0001)$ \\
HSP90 & CF180819 & 3.18 & $48.5(0.0321)$ \\
IL8 & NM_213867 & 5.58 & $35.5(0.0066)$ \\
HSP70 & NM_213766 & 11.06 & $31.4(0.0099)$ \\
TIMP1 & NM_213857 & 4.4 & $14.6(0.0023)$ \\
IL6 & AF493992 & 4.8 & $10.5(0.0074)$ \\
SOD2 & NM_214127 & 4.6 & $10.0(<0.0001)$ \\
NRAMP1 & U55068 & 3.97 & $7.2(0.0035)$ \\
SELE & NM_214268 & 3.5 & $5.9(0.0002)$ \\
PLAU & NM_213945 & 2.0 & $5.5(0.0415)$ \\
CCL19 & BX672579 & 2.16 & $4.2(0.0004)$ \\
haptocorrin & CB472702 & 3.78 & $2.1(0.0388)$ \\
TLR-2 & NM_213761 & 2.0 & $2.1(<0.0001)$ \\
ALOX15 & NM_213931 & 0.2 & $0.3(0.038)$ \\
\hline
\end{tabular}

oxide production, is involved in disruption of the bloodbrain barrier(BBB) in an experimental model of bacterial meningitis [61]. S. suis-mediated PGE2 production by human macrophages was also noticed by Jobin and contributed to the BBB disruption [62].

\section{Toll-like receptors (TLRs) pathway analysis}

Activation of the innate immune response is controlled in large part by the Toll-like receptor (TLR) family of pattern-recognition receptors. The previous study showed that $S$. suis was mainly recognized via TLR2 by THP-1 monocytes, which was associated with CD14 [38] and led to the release of pro-inflammatory mediators [63]. The strong activation of TLR2 and CD14 was also observed in murine brain parenchyma after the presence of S. suis bacteremia [39]. A recent research indicated that components released during $S$. suis infection as well as penicillin-treated whole bacteria could induce NF-kB activation through TLR2/6 [64]. The obvious elevation of TLR2 (2.0 fold) and CD14 (3.4 fold) was noticed at transcript level in spleens after highly pathogenic SS2 infection. Unsurprisingly, MyD88, an adaptor molecule in downstream signaling events with TLRs and CD14, was up-regulated at the level of 1.5 fold $(\mathrm{q}<10 \%)$. In contrast, the effect could not be seen with avirulent SS2 infection.

\section{Down-regulated transcripts following $S$. suis infection}

The majority of down-regulated genes were related to transcription, transport, material and energy metabolism (Table 1). Highly pathogenic strain could show high level of toxicity to host cells [34], and as a result, the influenced cells could hardly to be active. So these down regulations could be regarded the representative of the reduced vital activity of SS2-influenced cells.

\section{Discussion}

Two recent SS2 outbreaks in China not only seriously challenged public health but also shocked the scientific community, calling for the basic and translational studies of S. suis. Until now, several proteins were identified as vaccine candidates $[65,66]$ and drug targets $[67,68]$ for controlling SS2. In addition, emphasis is also extended to the pathogenesis study. Several pathogenic factors were successfully identified and strengthened the understanding for the virulence of the bacterium. As infectious disease resulted from the interplay between pathogens and the defense of the hosts they infect, host immune response was especially essential for understanding the diseases $[41,69]$.

In the present study, we tried to compare the gene expression profiles of spleens from swine suffering from highly pathogenic SS2, from swine infected with the avirulent isogenic strain, and from swine inoculated with PBS respectively to reveal the host immune response to SS2 and the contributions of host response to SS2 diseases. It is not accidental that significant changes of gene expression profiles could be noticed when infected with highly pathogenic SS2 compared with mock-infected samples, while avirulent isogenic strain would cause similar profiles to mock-infected samples (Figure 1A). These indicated that avirulent isogenic strain could hardly cause significant gene expression which was coincident with the fact that no significant clinical symptoms could be noticed in pigs. Moreover, the obvious changes in gene expression profiles were highly associated with significant clinical signs on day 3 post-inoculation with highly pathogenic strain. Further analysis of the present study indicated that the majority of down-regulated genes were mainly involved in transcription, transport, material and energy metabolism which were representative of the reduced vital activity of SS2-influenced cells. However, the up-regulated genes were principally related to immune response, such as genes involved in inflammatory response; acute-phase/immune response; cell adhesion and response to stress. Undoubtedly, it would be meaningful to explore the roles of these genes in SS2caused diseases.

First of all, it is necessary to know how SS2 induces immune response. It is well acknowledged that TLRs are transmembrane proteins that could recognize specific PAMPs and eventually result in the activation of NF$\mathrm{kB}$ and MAP kinases to elicit regulatory response [70]. Among these transmembrane proteins, TLR-2 could recognize bacterial LAM, BLP and PGN by following their initial interaction with CD14. Previous reports indicated that $S$. suis mainly induced proinflammatory 
cytokines by TLR2 of human macrophages and murine brain $[39,63]$, and several proinflammatory cytokines, such as IL-1B, IL-6, IL-8, TNF-a and MCP-1 could be triggered $[35,36,38,41]$. In our study, large doses of bacteria could be isolated from spleens of WT-infected pigs while no bacterium could be found to exist in pigs infected with $\triangle$ HP0197. In coincidence with these, TLR2 pathway and several proinflammatory cytokines were induced only in WT-infected pigs. $\triangle$ HP0197 showed similar transcript profile as control pigs due to either failing to invading or being easily eliminated by host. In contrast, the large doses of bacteria effected maximal cytokines release in WT-infected pigs [37]. The exaggerated high levels of cytokines perhaps exacerbate the inflammation and were considered to be responsible for $S$. suis caused diseases [39]. So the successful lethal pathogens could persistently induce cytokines secreted originally to clear the foreign invader, and as a result, the host's defense was utilized by S. suis to cause diseases, and to some extent to death.

As we all know that the secreted cytokine is an important part of a host defense system, which could recruit inflammatory cells to sites of tissue damage and help to eliminate the pathogens. However, this innate defense system is a double edged sword. If the recruiting inflammatory cells could kill the invader, the disease could be controlled. On the opposite side, if the recruiting phagocytes could not efficiently kill the bacteria, the tide would be turned to pathogen's favor, and the persistently induced cytokines would result in the exacerbated inflammation and lead to the death during the septic phase of infection. These might be the reason why the survival rate could be elevated when inflammation was inhibited by IL-10 [40], and why the level of cytokine was correlated inversely with survival time in patients with sepsis [45]. In coincidence with our analysis, pathogenic S. suis could effectively resist the uptake by phagocytes and CPS could inhibit activation of signaling pathways involved in phagocytosis $[17,71,72]$. In addition, several virulence-associated proteins such as FBPS [19], PDGA [31], LTA [30], HP0197 (unpublished data), serine protease [73] etc. were also contributed to the phagocytosis resistance, and the up-regulation of these proteins in vivo may suggest the better phagocytosis resistance $[31,74,75]$. Due to failing phagocytosis, bacteria could not only cause exacerbated inflammation but also contribute to its survival in the bloodstream in "modified Trojan Horse" theory in which bacteria travel extracellularly while attached to, but not phagocytosed [17,72], and then cause bacteremia and even septemia.

One of the key questions to be answered is how S. suis crosses the blood-brain barrier to cause meningitis, which was observed in all WT-infected pigs. The findings of the reported study presented that suilysin- positive strain could show toxin to produce functional alteration and increase the permeability of BBB; and Suilysin-negative strain might stimulate the production of proinflammatory cytokines resulting in alteration of $\mathrm{BBB}$ permeability $[76,77]$. And they also indicated that this highly pathogenic strain could produce high level of toxins in vivo-Suilysin, MRP, hyl [74], and undoubtedly it would contribute to the penetration of deep tissue and BBB. In addition, the stimulated production of proinflammatory cytokines would result in the alteration of BBB permeability, and it would be more feasible for $S$. suis to break through BBB. From our understanding, WT strain could utilize the synergic effect of toxins and high level of cytokines to accelerate the penetration of deep tissue and BBB. These might be the reason why the strain could cause severe human diseases in Sichuan, 2005.

\section{Conclusions}

Microarray technology has been used to analyse the globle porcine transcriptional response to infection with various pathogenic microorganisms recently. Study on the transcriptional response to the Gram-positive bacterium SS2 by using the Affymetrix GeneChip Porcine Genome Array has not been reported until now. Although great efforts have been made to understand the molecular basis of this infection, the response to SS2 infection is still largely unknown. Transcriptome analysis based on S. suis-infected spleens could improved the interference received by the cells analysis, and also supply the solid supplementary for analysis on alveolar macrophages. Highly pathogenic S. suis could persistently induce cytokines mainly by TLR2 pathway, and eventually the high level of cytokines and toxins secreted by phagocytosis-resistant bacteria could destroy deep tissues, and cause meningitis, septicaemia, pneumonia, endocarditis, and arthritis.

\section{Methods}

\section{Bacterial strains}

SS2 strain 05ZY (WT) which was isolated from the brain of a diseased piglet collected in Sichuan outbreak in China 2005 showed high virulence to pigs [4,78], and was applied to infect pigs. An isogenic HP0197 mutant ( $\triangle$ HP0197) derived strain 05ZY showed no obvious virulence to pigs (unpublished data) was applied as a control.

\section{Animals infection and tissue collection}

All the experimental protocols were approved by the Laboratory Animal Monitoring Committee of Hubei Province and performed accordingly. A total of 12 pigs of high-health status (ages 4-5 weeks) were assigned to three groups, within four in each. The pigs were 
determined to be SS2-free by antibody-based ELISA and nasal swabs-based bacteriologic test. One hour before inoculation, all pigs were given $2 \mathrm{ml}$ of $1 \%$ acetic acid (pH 2.9) intranasally to enhance the sensitivity of the S. suis challenge. Two groups were inoculated intranasally with $1 \mathrm{ml}$ of $2 \times 10^{6} \mathrm{CFU}$ of WT strain or $\triangle \mathrm{HP} 0197$ respectively, and the rest group inoculated with PBS was served as control. All pigs inoculated with WT showed typical symptoms at day 3 while pigs inoculated with $\triangle$ HP0197 or PBS showed no significant clinical signs. Blood samples from each group were detected for bacterial burden. Bacteria could be found in the blood of pigs in the WT group at day 3 post-inoculation while no bacterium was found from the blood of pigs inoculated with isogenic mutant strain or PBS at the same time point. All pigs were sacrificed at day 3 , and their tissue samples were cultured to prove in vivo bacterial burden. Bacteria were found in the spleens of the WT group, and no bacterium was found in the other two groups. Spleen samples were aseptically collected and immediately frozen in liquid nitrogen for future RNA isolation. Total RNA was isolated from approximately $200 \mathrm{mg}$ of each sample by using the TRIzol (Invitrogen) and RNeasy Midi kit (QIAGEN) based on the manufacturer's protocols. The integrity, quality, and quantity of RNA were assessed using the Agilent Bioanalyser 2100.

\section{Microarray hybridizations and data analysis}

The RNA labelling and hybridization were conducted by a commercial Affymetrix array service (CapitalBio Corp. Beijing, China). An aliquot of $2 \mu \mathrm{g}$ of total RNA was converted to double-stranded cDNA with the one-cycle cDNA Synthesis Kit (Affymetrix), and then biotin-tagged cRNA was produced with MessageAmp ${ }^{\text {sm }}$ II aRNA Amplification Kit. The resulting bio-tagged cRNA was fragmented to strands of 35 to 200 bases in length

Table 3 Primers for qPCR

\begin{tabular}{|c|c|c|c|}
\hline primer & $\begin{array}{l}\text { Accession } \\
\text { number }\end{array}$ & Sequence & $\begin{array}{l}\text { Product } \\
\text { size }\end{array}$ \\
\hline Plau & NM_213945 & $\begin{array}{l}\text { Forward: CGAACTGTGGCTGTCT } \\
\text { Reverse: AGCAGGTTTGCGATGTG }\end{array}$ & $126 \mathrm{bp}$ \\
\hline $5100 A 9^{a}$ & BI402402 & $\begin{array}{l}\text { Forward: CCAGGATGTGGTTTATGGCTTTC } \\
\text { Reverse: CGGACCAAATGTCGCAGA }\end{array}$ & $186 \mathrm{bp}$ \\
\hline$S 100 A 12^{a}$ & CB475695 & $\begin{array}{l}\text { Forward: GGCATTATGACACCCTTATC } \\
\text { Reverse: GTCACCAGGACCACGAAT }\end{array}$ & $169 \mathrm{bp}$ \\
\hline Hsp70 & NM_213766 & $\begin{array}{l}\text { Forward: AGGCGGAGAAGTACAAAGCG } \\
\text { Reverse: GATGGGGTTACACACCTGCTC }\end{array}$ & $257 \mathrm{bp}$ \\
\hline Timp 1 & NM_213857 & $\begin{array}{l}\text { Forward: CGCCTCGTACCAGCGTTAT } \\
\text { Reverse: GTGGAAGTATCCGCAGACGC }\end{array}$ & $127 \mathrm{bp}$ \\
\hline SOD2 & NM_214127 & $\begin{array}{l}\text { Forward: TCTGGACAAATCTGAGCCCT } \\
\text { Reverse: GACGGATACAGCGGTCAACTT }\end{array}$ & $119 \mathrm{bp}$ \\
\hline $116^{b}$ & AF493992 & $\begin{array}{l}\text { Forward: GACAAAGCCACCACCCCTAA } \\
\text { Reverse: CTCGTTCTGTGACTGCAGCTTATC }\end{array}$ & $69 \mathrm{bp}$ \\
\hline Sele & NM_214268 & $\begin{array}{l}\text { Forward: GGATTTGAACTCATCGGACCT } \\
\text { Reverse: CATTCTGAGGATGGCCGAC }\end{array}$ & $115 \mathrm{bp}$ \\
\hline $111 b^{b}$ & NM_214055 & $\begin{array}{l}\text { Forward: GGCCGCCAAGATATAACTGA } \\
\text { Reverse: GGACCTCTGGGTATGGCTTTC }\end{array}$ & $70 \mathrm{bp}$ \\
\hline Nramp 1 & U55068 & $\begin{array}{l}\text { Forward: CGTGGTGACAGGCAAGGACT } \\
\text { Reverse: TAGCCGTGCCGATGACTTC }\end{array}$ & $131 \mathrm{bp}$ \\
\hline Hsp90 & CF180819 & $\begin{array}{l}\text { Forward: CCCAGTTGATGTCGTTG } \\
\text { Reverse: CCGTCAGGCTTTCGTAT }\end{array}$ & $117 \mathrm{bp}$ \\
\hline $118^{b}$ & NM_213867 & $\begin{array}{l}\text { Forward: TTCGATGCCAGTGCATAAATA } \\
\text { Reverse: CTGTACAACCTTCTGCACCCA }\end{array}$ & $176 \mathrm{bp}$ \\
\hline CCL19 & BX672579 & $\begin{array}{l}\text { Forward: GCTAAGCCTCTGGACT } \\
\text { Reverse: AATGAGCAGGTAGCGA }\end{array}$ & $121 \mathrm{bp}$ \\
\hline Haptocorrin & CB472702 & $\begin{array}{l}\text { Forward: ATTCTCAGGGAGTATTCCGTCT } \\
\text { Reverse: CTTGGGGACAAGTAGCAGTT }\end{array}$ & $105 \mathrm{bp}$ \\
\hline Alox 15 & NM_213931 & $\begin{array}{l}\text { Forward: ACCGAGGGTTTCCTGTCT } \\
\text { Reverse: AGGTGGTTGGAGGAGTGC }\end{array}$ & $100 \mathrm{bp}$ \\
\hline$T L R 2^{b}$ & NM_213761 & $\begin{array}{l}\text { Forward:TCACTTGTCTAACTTATCATCCTCTTG } \\
\text { Reverse: TCAGCGAAGGTGTCATTATTGC }\end{array}$ & $162 \mathrm{bp}$ \\
\hline$G A P D H^{b}$ & AF017079 & $\begin{array}{l}\text { Forward: TGCCAACGTGTCGGTTGT } \\
\text { Reverse: TGTCATCATATTTGGCAGGTTTCT }\end{array}$ & $62 \mathrm{bp}$ \\
\hline
\end{tabular}

a: primers from reference [43];

$b$ : primers from reference [41]. 
according to Affymetrix's protocols and then it was hybridized to GeneChip Porcine Genome Array. Hybridization was performed at $45^{\circ} \mathrm{C}$ with rotation for $16 \mathrm{~h}$ (Affymetrix GeneChip Hybridization Oven 640). The GeneChip arrays were washed and then stained (streptavidin-phycoerythrin) on an Affymetrix Fluidics Station 450 followed by scanning on GeneChip Scanner 3000 .

The hybridization data were analyzed using GeneChip Operating software (GCOS 1.4). A global scaling factor of 500 was used to normalize the different arrays. We identified the differentially expressed genes according to change p-value calculated by GCOS 1.4, and 2-fold change as an empirical criterion. Then all DE genes were performed for hierarchical cluster (Ver.3.0) and TreeView (Ver.1.1.1) analyses. Genes with significant similarities to transcripts in $\mathrm{nr}$ database based on BLASTX searches were selected for GO analysis with DAVID http://david.abcc.ncifcrf.gov/ home.jsp. Annotation results were obtained by inputting the gene list of ENTREZ_GENE_ID as identifier. All microarray results from this study were deposited in NCBI's Gene Expression Omnibus (GEO) database, accession numbers are: Platform, GPL3533; Series, GSE23596; Samples, GSM578704, GSM578705, GSM578706, GSM578707, GSM578708, GSM578709, GSM578710, GSM578711, GSM578712.

\section{qPCR analysis}

All tested RNAs from swine spleens were reversely transcribed to cDNA with the M-MLV Reverse Transcriptase (Promega). Each cDNA sample was used as a template for qPCR and the amplification mixture contained SYBR Green (TOYOBO, Japan), forward and reverse primers. Some primers were designed by the program Primer 5.0, the primer names, accession number, primer sequence and product size are shown in Table 3. The efficiency of the PCR reaction was $91-99 \%$ for all reactions (slope standard line between -3.3 and -3.6). The standard line consisted of five 10-fold dilutions of the samples. Analysis was performed using the ABI7500 Software (Applied Biosystems). PCRs were performed in ABI PRISM 7500 sequence detection system as follows: 1 cycle at $95^{\circ} \mathrm{C}$ for $10 \mathrm{~min} ; 45$ cycles at $95^{\circ} \mathrm{C}$ for $30 \mathrm{~s}, 60^{\circ} \mathrm{C}$ for $30 \mathrm{~s}$ and $72^{\circ} \mathrm{C}$ for $30 \mathrm{~s}$. Melting curves were performed at the end of amplification for validating data quality by increasing the temperature from $65^{\circ}$ $\mathrm{C}$ to $95^{\circ} \mathrm{C}$, read every $0.2^{\circ} \mathrm{C}$, hold $2 \mathrm{sec}$, then cooling at $25^{\circ} \mathrm{C}$ for $30 \mathrm{~s}$. The PCR products were confirmed using agarose gel electrophoresis (1.5\%). Amplification of the gapdh gene was used as internal control. All the tested genes are shown in Table 3. All reactions were performed in triplicate. For each run, to normalize the amount of sample cDNA added to each reaction, the $C t$ value of each test gene was subtracted by the $C t$ value of the endogenous control gapdh gene (delta $C t=C t$ tested gene - Ct gapdh), and then for a comparison between the expression of the gene in treated samples and in control samples. The delta $C t$ values of the gene in treated samples were subtracted by the delta $C t$ value of the gene in control samples (delta-delta $C t=$ delta $C t$ treatment - delta $C t$ control). The fold changes were calculated by the formula of $2^{\text {-delta-delta } C t}$ described by Livak \& Schmittgen [79]. Data were means \pm SD of triplicate reactions for each gene transcript.

\section{Additional material}

Additional file 1: Spleen transcriptome analysis following S. suis

infection using the Affymetrix Porcine Genechip. Data of each probe is from the three piglets of the control group (NC-1P, NC-2P, NC-3P), the WT group (WT-1P, WT-2P, WT-3P) and the $\triangle$ HP0197 group (M97-1P, M97$2 P, M 97-3 P$ ). " $P$ ", present; " $A$ ", absent; " $M$ ", marginal; select while Count (P) $\geq 2$ in two groups. Totally, 15,757, 14,992 and 15,487 probesets were detected expression in the control group, the WT group and $\triangle$ HP0197 group respectively.

Additional file 2: transcripts expressed in porcine spleen following S. suis (WT) infection. "FC", Fold change, gene expression level following WT infection compared to the control. " $\geq 2$ " represents up regulation, " $<1$ " represents down regulation. " $q$-value", significance level of differential expression for a particular gene. "Gene description", top informative BLASTX hit.

Additional file 3: Differentially expressed transcripts in porcine spleen following S. suis (WT) infection (q < 10\%, FC $\geq 2$ ). 120 transcripts (row 5-124) were significantly up-regulated, and 132 (row 125256) were significantly down-regulated, "FC", Fold change, gene expression level following WT infection compared to the control.

\section{Abbreviations}

SS2: Streptococcus suis serotype 2; DE: differentially expressed; FC: fold change; GO: Gene Ontology; FDR: false discovery rate; qPCR: quantitative real-time PCR; TLR: Toll-like receptors; PRRs: pattern-recognition receptors.

\section{Acknowledgements}

We thank Professor Yanxiu Liu for her revision of the language of this manuscript.

This work was supported by National Basic Research Program of China (program 973, grant 2006CB504404), the National Transgenic Major Program (2009ZX08009-141B), the National Natural Science Foundation of China (30871870), and Program for Changjiang Scholars and Innovative Research Team in University (IRT0726).

\section{Author details}

${ }^{1}$ Unit of Animal Infectious Diseases, National Key Laboratory of Agricultural Microbiology, Huazhong Agricultural University, Wuhan, Hubei, China. ${ }^{2}$ College of Veterinary Medicine, Huazhong Agricultural University, Wuhan, Hubei, China.

\section{Authors' contributions}

$\mathrm{RL}$ and $\mathrm{BC}$ carried out all works and drafted the manuscript. AZ made substantial contributions to bioinformatics and statistical analysis. LT and YW participated in the animal challenge experiment. HC participated in the experiment design and coordination. MJ helped to revise and finalize the manuscript. All authors read and approved the final manuscript.

Received: 4 May 2010 Accepted: 11 October 2010 Published: 11 October 2010 


\section{References}

1. Staats JJ, Feder I, Okwumabua O, Chengappa MM: Streptococcus suis: past and present. Vet Res Commun 1997, 21(6):381-407.

2. Lun ZR, Wang QP, Chen XG, Li AX, Zhu XQ: Streptococcus suis: an emerging zoonotic pathogen. Lancet Infect Dis 2007, 7(3):201-209.

3. Hill JE, Gottschalk M, Brousseau R, Harel J, Hemmingsen SM, Goh SH: Biochemical analysis, cpn60 and 16S rDNA sequence data indicate that Streptococcus suis serotypes 32 and 34, isolated from pigs, are Streptococcus orisratti. Vet Microbiol 2005, 107(1-2):63-69.

4. Tang J, Wang C, Feng Y, Yang W, Song H, Chen Z, Yu H, Pan X, Zhou X, Wang $H$, et al: Streptococcal toxic shock syndrome caused by Streptococcus suis serotype 2. PLoS Med 2006, 3(5):e151

5. Vanier G, Segura M, Lecours MP, Grenier D, Gottschalk M: Porcine brain microvascular endothelial cell-derived interleukin-8 is first induced and then degraded by Streptococcus suis. Microb Pathog 2009, 46(3):135-143.

6. Haas G, Karaali G, Ebermayer K, Metzger WG, Lamer S, Zimny-Arndt U, Diescher S, Goebel UB, Vogt K, Roznowski AB, et al: Immunoproteomics of Helicobacter pylori infection and relation to gastric disease. Proteomic 2002, 2(3):313-324.

7. Holden MT, Hauser H, Sanders M, Ngo TH, Cherevach I, Cronin A Goodhead I, Mungall K, Quail MA, Price C, et al: Rapid evolution of virulence and drug resistance in the emerging zoonotic pathogen Streptococcus suis. PLoS One 2009, 4(7):e6072

8. Wangsomboonsiri W, Luksananun T, Saksornchai S, Ketwong K, Sungkanuparph S: Streptococcus suis infection and risk factors for mortality. J Infect 2008, 57(5):392-396

9. Rusmeechan S, Sribusara P: Streptococcus suis meningitis: the newest serious infectious disease. J Med Assoc Thai 2008, 91(5):654-658.

10. Watkins EJ, Brooksby P, Schweiger MS, Enright SM: Septicaemia in a pigfarm worker. Lancet 2001, 357(9249):38

11. Taipa $R$, Lopes $V$, Magalhaes M: Streptococcus suis meningitis: first case report from Portugal. J Infect 2008, 56(6):482-483.

12. Tramontana AR, Graham M, Sinickas V, Bak N: An Australian case of Streptococcus suis toxic shock syndrome associated with occupational exposure to animal carcasses. Med J Aust 2008, 188(9):538-539.

13. van de Beek D, Spanjaard L, de Gans J: Streptococcus suis meningitis in the Netherlands. J Infect 2008, 57(2):158-161.

14. Smith TC, Capuano AW, Boese B, Myers KP, Gray GC: Exposure to Streptococcus suis among US swine workers. Emerg Infect Dis 2008, 14(12):1925-1927.

15. Fittipaldi N, Collis T, Prothero B, Gottschalk M: Streptococcus suis Meningitis, Hawaii. Emerg Infect Dis 2009, 15(12):2067-2069.

16. Wertheim HF, Nguyen HN, Taylor W, Lien TT, Ngo HT, Nguyen TQ, Nguyen BN, Nguyen HH, Nguyen HM, Nguyen CT, et al: Streptococcus suis, an important cause of adult bacterial meningitis in northern Vietnam. Plos One 2009, 4(6), e5973.

17. Chabot-Roy G, Willson P, Segura M, Lacouture S, Gottschalk M: Phagocytosis and killing of Streptococcus suis by porcine neutrophils. Microb Pathog 2006, 41(1):21-32.

18. Smith HE, Damman M, van der Velde J, Wagenaar F, Wisselink HJ Stockhofe-Zurwieden N, Smits MA: Identification and characterization of the cps locus of Streptococcus suis serotype 2: the capsule protects against phagocytosis and is an important virulence factor. Infect Immun 1999, 67(4):1750-1756.

19. de Greeff A, Buys H, Verhaar R, Dijkstra J, van Alphen L, Smith HE: Contribution of fibronectin-binding protein to pathogenesis of Streptococcus suis serotype 2. Infect Immun 2002, 70(3):1319-1325.

20. Brassard J, Gottschalk M, Quessy S: Cloning and purification of the Streptococcus suis serotype 2 glyceraldehyde-3-phosphate dehydrogenase and its involvement as an adhesin. Vet Microbiol 2004 102(1-2):87-94

21. Esgleas M, Li Y, Hancock MA, Harel J, Dubreuil JD, Gottschalk M: Isolation and characterization of alpha-enolase, a novel fibronectin-binding protein from Streptococcus suis. Microbiology 2008, 154(Pt 9):2668-2679.

22. Zhang $A$, Chen $B$, Mu X, Li R, Zheng $P$, Zhao $Y$, Chen $H$, Jin $M$ : Identification and characterization of a novel protective antigen, Enolase of Streptococcus suis serotype 2. Vaccine 2009, 27(9):1348-1353.

23. Haataja S, Tikkanen K, Hytonen J, Finne J: The Gal alpha 1-4 Gal-binding adhesin of Streptococcus suis, a gram-positive meningitis-associated bacterium. Adv Exp Med Biol 1996, 408:25-34.
24. Haataja S, Tikkanen K, Liukkonen J, Francois-Gerard C, Finne J: Characterization of a novel bacterial adhesion specificity of Streptococcus suis recognizing blood group $\mathrm{P}$ receptor oligosaccharides. J Biol Chem 1993, 268(6):4311-4317

25. Haataja S, Tikkanen K, Nilsson U, Magnusson G, Karlsson KA, Finne J: Oligosaccharide-receptor interaction of the Gal alpha 1-4Gal binding adhesin of Streptococcus suis. Combining site architecture and characterization of two variant adhesin specificities. J Biol Chem 1994 269(44):27466-27472

26. Tikkanen K, Haataja S, Francois-Gerard C, Finne J: Purification of a galactosyl-alpha 1-4-galactose-binding adhesin from the gram-positive meningitis-associated bacterium Streptococcus suis. J Biol Chem 1995, 270(48):28874-28878

27. Tikkanen K, Haataja S, Finne J: The galactosyl-(alpha 1-4)-galactosebinding adhesin of Streptococcus suis: occurrence in strains of different hemagglutination activities and induction of opsonic antibodies. Infect Immun 1996, 64(9):3659-3665.

28. Baums CG, Kaim U, Fulde M, Ramachandran G, Goethe R, ValentinWeigand $P$ : Identification of a novel virulence determinant with serum opacification activity in Streptococcus suis. Infect Immun 2006, 74(11):6154-6162.

29. Zhang A, Mu X, Chen B, Liu C, Han L, Chen H, Jin M: Identification and characterization of $\lg \mathrm{A} 1$ protease from Streptococcus suis. Vet Microbiol 2010, 140(1-2):171-175

30. Fittipaldi N, Sekizaki T, Takamatsu D, Harel J, Dominguez-Punaro Mde L, Von Aulock S, Draing C, Marois C, Kobisch M, Gottschalk M: D-alanylation of lipoteichoic acid contributes to the virulence of Streptococcus suis. Infect Immun 2008, 76(8):3587-3594.

31. Fittipaldi N, Sekizaki T, Takamatsu D, Dominguez-Punaro Mde L, Harel J, Bui NK, Vollmer W, Gottschalk M: Significant contribution of the pgdA gene to the virulence of Streptococcus suis. Mol Microbiol 2008, 70(5):1120-1135

32. Li M, Wang C, Feng Y, Pan X, Cheng G, Wang J, Ge J, Zheng F, Cao M, Dong $Y$, et al: SalK/SalR, a two-component signal transduction system, is essential for full virulence of highly invasive Streptococcus suis serotype 2. PLOS ONE 2008, 3(5):e2080.

33. Pan X, Ge J, Li M, Wu B, Wang C, Wang J, Feng Y, Yin Z, Zheng F, Cheng G, et al: The orphan response regulator CovR: a globally negative modulator of virulence in Streptococcus suis serotype 2. J Bacteriol 2009, 191(8):2601-2612.

34. Ye $C$, Zheng $H$, Zhang J, Jing $H$, Wang L, Xiong $Y$, Wang W, Zhou Z, Sun $Q$, Luo $X$, et al: Clinical, Experimental, and Genomic Differences between Intermediately Pathogenic, Highly Pathogenic, and Epidemic Streptococcus suis. J Infect Dis 2009, 199(1):97-107.

35. Vadeboncoeur N, Segura M, Al-Numani D, Vanier G, Gottschalk M: Proinflammatory cytokine and chemokine release by human brain microvascular endothelial cells stimulated by Streptococcus suis serotype 2. FEMS Immunol Med Microbiol 2003, 35(1):49-58.

36. Segura M, Vanier G, Al-Numani D, Lacouture S, Olivier M, Gottschalk M: Proinflammatory cytokine and chemokine modulation by Streptococcus suis in a whole-blood culture system. FEMS Immunol Med Microbiol 2006, 47(1):92-106

37. Segura M, Stankova J, Gottschalk M: Heat-killed Streptococcus suis capsular type 2 strains stimulate tumor necrosis factor alpha and interleukin-6 production by murine macrophages. Infect Immun 1999, 67(9):4646-4654.

38. Segura M, Vadeboncoeur N, Gottschalk M: CD14-dependent and -independent cytokine and chemokine production by human THP-1 monocytes stimulated by Streptococcus suis capsular type 2. Clin Exp Immunol 2002, 127(2):243-254.

39. Dominguez-Punaro MC, Segura M, Plante MM, Lacouture S, Rivest $S$, Gottschalk M: Streptococcus suis serotype 2, an important swine and human pathogen, induces strong systemic and cerebral inflammatory responses in a mouse model of infection. J Immunol 2007, 179(3):1842-1854.

40. Dominguez-Punaro Mde L, Segura M, Radzioch D, Rivest S, Gottschalk M: Comparison of the susceptibilities of $\mathrm{C} 57 \mathrm{BL} / 6$ and $\mathrm{A} / \mathrm{J}$ mouse strains to Streptococcus suis serotype 2 infection. Infect Immun 2008, 76(9):3901-3910.

41. de Greeff A, Benga L, Wichgers Schreur PJ, Valentin-Weigand P, Rebel JM, Smith HE: Involvement of NF-kappaB and MAP-kinases in the 
transcriptional response of alveolar macrophages to Streptococcus suis. Vet Microbiol 2009, 141(1-2):59-67.

42. Zhao SH, Kuhar D, Lunney JK, Dawson H, Guidry C, Uthe JJ, Bearson SM, Recknor J, Nettleton D, Tuggle CK: Gene expression profiling in Salmonella Choleraesuis-infected porcine lung using a long oligonucleotide microarray. Mamm Genome 2006, 17(7):777-789.

43. Chen H, Li C, Fang M, Zhu M, Li X, Zhou R, Li K, Zhao S: Understanding Haemophilus parasuis infection in porcine spleen through a transcriptomics approach. BMC Genomics 2009, 10:64.

44. van der Poll T, Keogh CV, Guirao X, Buurman WA, Kopf M, Lowry SF: Interleukin-6 gene-deficient mice show impaired defense against pneumococcal pneumonia. J Infect Dis 1997, 176(2):439-444.

45. Norrby-Teglund A, Pauksens K, Norgren M, Holm SE: Correlation between serum TNF alpha and IL6 levels and severity of group A streptococcal infections. Scand J Infect Dis 1995, 27(2):125-130.

46. Foell $D$, Wittkowski $H$, Vogl T, Roth J: $\mathrm{S} 100$ proteins expressed in phagocytes: a novel group of damage-associated molecular pattern molecules. J Leukoc Biol 2007, 81(1):28-37.

47. Hojo K, Tamura A, Mizoguchi C, Kato D, Ohshima T, Maeda N: Predominant bacteria recovered from a periodontitis site in a hamster model raised by silk-ligature with Porphyromonas gingivalis infection. Biosci Biotechnol Biochem 2008, 72(5):1348-1351.

48. Patel L, Buckels AC, Kinghorn IJ, Murdock PR, Holbrook JD, Plumpton C, Macphee CH, Smith SA: Resistin is expressed in human macrophages and directly regulated by PPAR gamma activators. Biochem Biophys Res Commun 2003, 300(2):472-476.

49. Bokarewa M, Nagaev I, Dahlberg L, Smith U, Tarkowski A: Resistin, an adipokine with potent proinflammatory properties. J Immunol 2005, 174(9):5789-5795.

50. Ward PP, Conneely OM: Lactoferrin: role in iron homeostasis and host defense against microbial infection. Biometals 2004, 17(3):203-208.

51. Knura-Deszczk S, Lipperheide C, Petersen B, Jobert JL, Berthelot-Herault F, Kobisch M, Madec F: Plasma haptoglobin concentration in swine after challenge with Streptococcus suis. J Vet Med B Infect Dis Vet Public Health 2002, 49(5):240-244.

52. Thorn CF, Lu ZY, Whitehead AS: Tissue-specific regulation of the human acute-phase serum amyloid A genes, SAA1 and SAA2, by glucocorticoids in hepatic and epithelial cells. Eur J Immunol 2003, 33(9):2630-2639.

53. Baumann H, Gauldie J: The acute phase response. Immunol Today 1994, 15(2):74-80.

54. Sorensen NS, Tegtmeier C, Andresen LO, Pineiro M, Toussaint MJ, Campbell FM, Lampreave F, Heegaard PM: The porcine acute phase protein response to acute clinical and subclinical experimental infection with Streptococcus suis. Vet Immunol Immunopathol 2006, 113(1-2):157-168.

55. Rikitake $Y$, Takai $Y$ : Interactions of the cell adhesion molecule nectin with transmembrane and peripheral membrane proteins for pleiotropic functions. Cell Mol Life Sci 2008, 65(2):253-263.

56. Al-Numani D, Segura M, Dore M, Gottschalk M: Up-regulation of ICAM-1, CD11a/CD18 and CD11C/CD18 on human THP-1 monocytes stimulated by Streptococcus suis serotype 2. Clin Exp Immunol 2003, 133(1):67-77.

57. Wight TN: Versican: a versatile extracellular matrix proteoglycan in cell biology. Curr Opin Cell Biol 2002, 14(5):617-623.

58. Wang W, Xu GL, Jia WD, Ma JL, Li JS, Ge YS, Ren WH, Yu JH, Liu WB: Ligation of TLR2 by versican: a link between inflammation and metastasis. Arch Med Res 2009, 40(4):321-323.

59. Simantov R, Silverstein RL: CD36: a critical anti-angiogenic receptor. Front Biosci 2003, 8:s874-882

60. Nakache M, Berg EL, Streeter PR, Butcher EC: The mucosal vascular addressin is a tissue-specific endothelial cell adhesion molecule for circulating lymphocytes. Nature 1989, 337(6203):179-181.

61. Tilley SL, Coffman TM, Koller BH: Mixed messages: modulation of inflammation and immune responses by prostaglandins and thromboxanes. J Clin Invest 2001, 108(1):15-23.

62. Jobin MC, Gottschalk M, Grenier D: Upregulation of prostaglandin E2 and matrix metalloproteinase 9 production by human macrophage-like cells: synergistic effect of capsular material and cell wall from Streptococcus suis. Microb Pathog 2006, 40(1):29-34.

63. Graveline R, Segura M, Radzioch D, Gottschalk M: TLR2-dependent recognition of Streptococcus suis is modulated by the presence of capsular polysaccharide which modifies macrophage responsiveness. Int Immunol 2007, 19(4):375-389.
64. Schreur PJ, Rebel JM, Smits MA, van Putten JP, Smith HE: Differential activation of the Toll-like receptor $2 / 6$ complex by lipoproteins of Streptococcus suis serotypes 2 and 9. Vet Microbiol 143(2-4):363-370.

65. Baums CG, Valentin-Weigand P: Surface-associated and secreted factors of Streptococcus suis in epidemiology, pathogenesis and vaccine development. Anim Health Res Rev 2009, 10(1):65-83.

66. Feng $Y$, Zhang $H, M a Y, G a o$ GF: Uncovering newly emerging variants of Streptococcus suis, an important zoonotic agent. Trends Microbiol 2010, 18(3):124-31.

67. Zhang Q, Peng H, Gao F, Liu Y, Cheng H, Thompson J, Gao GF: Structural insight into the catalytic mechanism of gluconate 5-dehydrogenase from Streptococcus suis: Crystal structures of the substrate-free and quaternary complex enzymes. Protein Sci 2009, 18(2):294-303.

68. Zhang Q, Gao F, Peng H, Cheng H, Liu Y, Tang J, Thompson J, Wei G, Zhang J, Du Y, et al: Crystal structures of Streptococcus suis mannonate dehydratase (ManD) and its complex with substrate: genetic and biochemical evidence for a catalytic mechanism. J Bacteriol 2009, 191(18):5832-7.

69. Goldmann O, von Kockritz-Blickwede M, Holtje C, Chhatwal GS, Geffers R, Medina E: Transcriptome analysis of murine macrophages in response to infection with Streptococcus pyogenes reveals an unusual activation program. Infect Immun 2007, 75(8):4148-4157.

70. Akira S, Uematsu S, Takeuchi O: Pathogen recognition and innate immunity. Cell 2006, 124(4):783-801.

71. Segura M, Gottschalk M: Streptococcus suis interactions with the murine macrophage cell line J774: adhesion and cytotoxicity. Infect Immun 2002, 70(8):4312-4322

72. Segura M, Gottschalk M, Olivier M: Encapsulated Streptococcus suis inhibits activation of signaling pathways involved in phagocytosis. Infect Immun 2004, 72(9):5322-5330.

73. Hu Q, Liu P, Yu Z, Zhao G, Li J, Teng L, Zhou M, Bei W, Chen H, Jin M: Identification of a cell wall-associated subtilisin-like serine protease involved in the pathogenesis of Streptococcus suis serotype 2. Microb Pathog 2010, 48(3-4):103-9.

74. Tan C, Liu M, Jin M, Liu J, Chen Y, Wu T, Fu T, Bei W, Chen H: The key virulence-associated genes of Streptococcus suis type 2 are upregulated and differentially expressed in vivo. FEMS Microbiol Lett 2008, 278(1):108-114.

75. Zhang A, Chen B, Li R, Mu X, Han L, Zhou H, Chen H, Meilin J: Identification of a surface protective antigen, HP0197 of Streptococcus suis serotype 2. Vaccine 2009, 27(38):5209-5213.

76. Gottschalk M, Segura M: The pathogenesis of the meningitis caused by Streptococcus suis: the unresolved questions. Vet Microbiol 2000, 76(3):259-272.

77. Vanier G, Segura M, Friedl P, Lacouture S, Gottschalk M: Invasion of porcine brain microvascular endothelial cells by Streptococcus suis serotype 2 . Infect Immun 2004, 72(3):1441-1449.

78. Zhang A, Xie C, Chen H, Jin M: Identification of immunogenic cell wallassociated proteins of Streptococcus suis serotype 2. Proteomics 2008, 8(17):3506-3515

79. Livak KJ, Schmittgen TD: Analysis of relative gene expression data using real-time quantitative PCR and the 2(-Delta Delta C(T)) Method. Methods 2001, 25(4):402-408.

\section{doi:10.1186/1471-2164-11-556}

Cite this article as: Li et al:: Response of swine spleen to Streptococcus suis infection revealed by transcription analysis. BMC Genomics 2010 11:556. 